\title{
COMPARISON OF NUMERICAL SIMULATION RESULTS FOR TRANSPORT AND THERMODYNAMIC PROPERTIES OF THE SOLID FUELS COMBUSTION PRODUCTS WITH EXPERIMENTAL DATA
}

\begin{abstract}
Yuriy SHMELKOV, Eugueny SAMUJLOV*
Abstract: Comparison of calculation results of transport properties of the solid fuels combustion products was made with known experimental data. Calculation was made by means of the modified program TETRAN developed in G.M. Krzhizhanovsky Power Engineering Institute. The calculation was spent with chemical reactions and phase transformations occurring during combustion. Also ionization of products of solid fuels combustion products at high temperatures was taken into account. In the capacity of fuels various Russian coals and some other solid fuels were considered. As a result of density, viscosity and heat conductivity calculation of a gas phase of solid fuels combustion products the data has been obtained in a range of temperatures 500-20000 K. This comparison has shown good convergence of calculation results with experiment.
\end{abstract}

\section{INTRODUCTION}

Products of solid fuels combustion is difficult multicomponent system. Calculation of structure and properties of such system is an interesting and important problem. Similar researches can help to predict a course of reactions at phase and chemical transformations. The method and algorithm for calculation of solid fuels combustion products concentration and for calculation of transport properties is resulted lower and in previous papers. On the basis of this method, by means of modernized program TETRAN, the data on structure of various coal combustion products has been obtained and comparison of transport properties calculation results with known experimental data for pure gases, and for mixes is spent.

\section{Method AND ALGORITHM}

The system consisting from $n$ components is considered. A current index of component number from $n$ we designate $i(i=1,2,3 \ldots n)$, current indexes of phase number from $r$ we designate $\gamma, \beta \quad(\gamma, \beta=1,2,3 \ldots r)$. From a set of all components $n$ we can allocate $k$ linearly independent components. A current index of linearly independent components from $k$ we designate $j(j=1,2,3 \ldots k)$. Any of $i$ components can be expressed through linearly independent components $j$ by means of set of stoichiometric factors $\Phi_{i j}$. It is possible to form a rectangular matrix $\left\|\Phi_{i j}\right\|$ of these stoichiometric

\footnotetext{
- Shmelkov Yuriy, Russia, Moscow, YurezSml@mail.ru; Samujlov Eugueny, Russia, Moscow, evsam@eninnet.ru
} 
factors. If we designate a chemical symbol as $A_{i}^{\gamma}$, that
$A_{i}^{\gamma}=\sum_{\beta} \sum_{j(\beta)} \Phi_{i(\gamma) j(\beta)^{A}}{ }_{j(\beta)}$, where $A_{j(\beta)}$ is basic components of $j(\beta)$, somehow distributed on $r$ phases. For a finding the solid fuels combustion products structure the system of chemical thermodynamic equations for numbers of moles $N_{i}^{\gamma}$ all a component is uses. This system looking like:

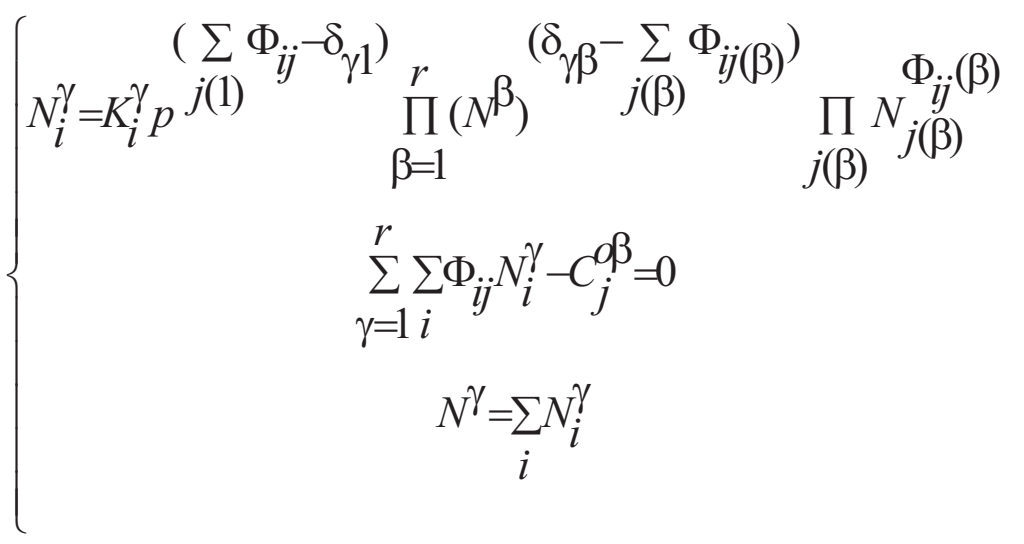

Types of the condensed phases are set preliminary, and their number is defined by Gibbs phase rule $w=2+k-r$. The system of the nonlinear algebraic equations as a result of transformations is reduced to system of the iterative linear equations concerning logarithmic amendments for numbers of moles of linearly independent components which number is equal to number of various atoms in system, and full numbers of moles of the various condensed phases. Number of these equations much less than full number of the chemical thermodynamic equations. Algorithm of the linear iterative equations system decision is universal for change of quantity or structure of the condensed phases. Calculation is conducted, beginning from high temperatures where the concentrations of system atoms are set as initial approximation. Calculation is conducted simultaneously for two pairs independent parameters: $V, T$ and $P, T$. In case of occurrence of problems with process convergence on one of pairs of variables the program automatically continues to consider and give out correct results only on variables $V, T$ or $P, T$. After several steps on temperature «the bad point» manages and further calculation again on two pairs of variables is made. The program is provided by base of the thermodynamic given individual substances formed as a result of various reactions more than for 3000 substances.

The transport phenomenon in the gas phase in most cases satisfactorily describes Chapman-Enskog theory developed in the physical kinetics of gases for neutral gas [1], and further developed in the works $[2,3]$.

For multi-component mixtures the expression for the coefficient of dynamic viscosity may be written as:

$$
\eta=-1.186 \cdot 10^{-5} T^{1 / 2}\left|\begin{array}{cc}
H_{i j} & x_{i} \\
x_{j} & 0
\end{array}\right| \times\left|H_{i j}\right|^{-1}
$$




$$
\begin{gathered}
H_{i i}=x_{i}^{2} M_{i i}^{-1 / 2} Q_{i i} A_{i i}^{*}+\sum_{l \neq i} 2 x_{i} x_{l} M_{i l}^{1 / 2}\left(M_{i}+M_{l}\right)^{-1} Q_{i l}\left(\frac{5}{3}+A_{i l}^{*} \frac{M_{l}}{M_{i}}\right), \text { при } i=j \\
H_{i j}=-2 x_{i} x_{j} M_{i j}^{1 / 2}\left(M_{i}+M_{j}\right)^{-1 / 2} Q_{i j}\left(\frac{5}{3}-A_{i j}^{*}\right), \text { при } i \neq j \\
M_{i j}=\frac{M_{i} M_{j}}{M_{i}+M_{j}}, Q_{i j}=\pi \sigma_{i j}^{2} \Omega_{i j}^{(1,1)^{*}}, A_{i j}^{*}=\frac{\Omega_{i j}^{(2,2)^{*}}}{\Omega_{i j}^{(1,1)^{*}}} .
\end{gathered}
$$

The kinematic viscosity coefficient and density shall be calculated in the following proportions:

$$
v=\frac{\eta}{\rho}, \rho=12.1878 \frac{p}{T} \sum_{i} x_{i} M_{i} .
$$

At heat conductivity calculation the big role have internal degrees of freedom and inelastic collisions of particles, including the collisions leading to chemical transformations. If inelastic collisions are frequent and probability of chemical reactions is great enough, so all components of gas are in local balance, with the big accuracy it is possible to use following expressions for forward heat conductivity of heavy components $\lambda_{H}$, internal heat conductivity $\lambda_{\text {int }}$ and reaction heat conductivity $\lambda_{R}$ :

$$
\begin{gathered}
\lambda=\lambda_{H}+\lambda_{e}+\lambda_{\text {int }}+\lambda_{R} \text { (5) } \\
\lambda_{H}=0.7392 T^{1 / 2}\left|\begin{array}{cc}
L_{i j} & x_{i}+y_{i} \\
x_{j} & 0
\end{array}\right| \times\left|L_{i j}\right|^{-1} \\
\lambda_{i n t}=0.05914 T^{1 / 2} \sum_{i} C_{i, \text { int }_{i}} x_{i i}^{-1}+0.7392 T^{1 / 2}\left|\begin{array}{cc}
L_{i j} & x_{i} \\
x_{j}+y_{j} & 0
\end{array}\right| \times\left|L_{i j}\right|^{-1} \\
\lambda_{R}=-7.969 \cdot 10^{6} T^{-3 / 2}\left|\begin{array}{cc}
a_{i j} & \Delta H_{i} \\
\Delta H_{j} & 0
\end{array}\right| \times\left|a_{i j}\right|^{-1}
\end{gathered}
$$

More details about method to calculate the composition and thermal properties is described in the article [4].

\section{Results}

In this work comparison of calculation results of dynamic viscosity and heat conductivity with experimental data for nitrogen, water vapor and air is resulted. Data for comparison was received from the site of NIST (http://webbook.nist.gov/chemistry/) and from the book [5]. In Fig. 1 comparison of the nitrogen dynamic viscosity with experiment is shown. The maximum calculation error makes $11 \%$. 


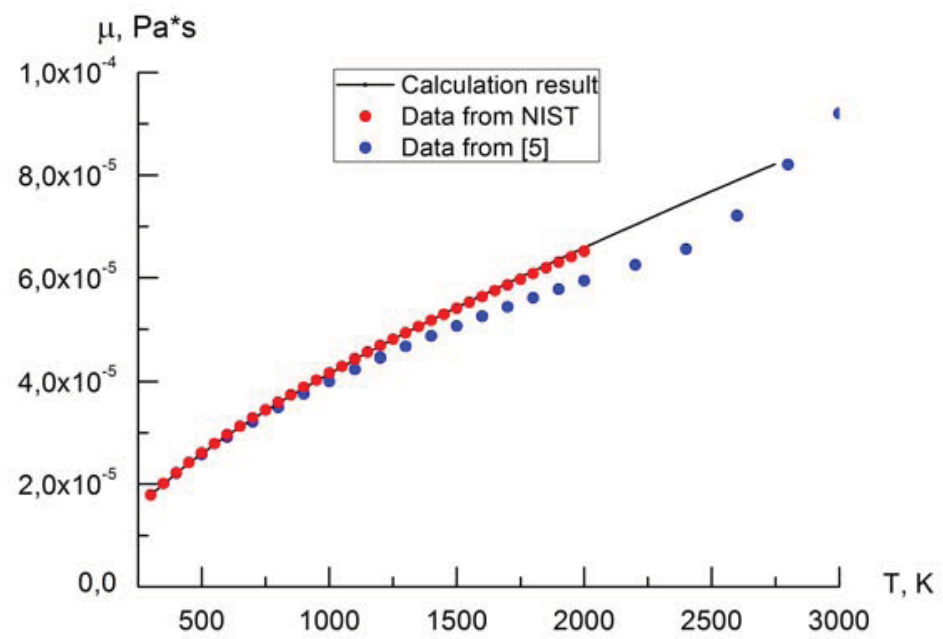

Figure 1: Comparison of dynamic viscosity with experimental data for nitrogen

In Fig. 2 comparison of the nitrogen heat conductivity with experimental data is shown. The maximum calculation error makes $12 \%$.

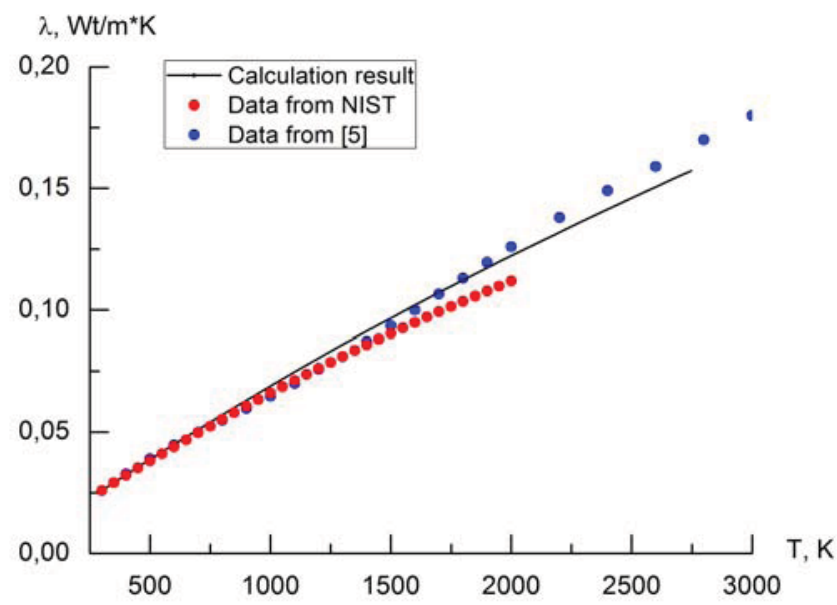

Figure 2: Comparison of heat conductivity with experimental data for nitrogen

In Fig. 3 comparison of vapor dynamic viscosity with experimental data is shown. The maximum calculation error makes $10 \%$. 


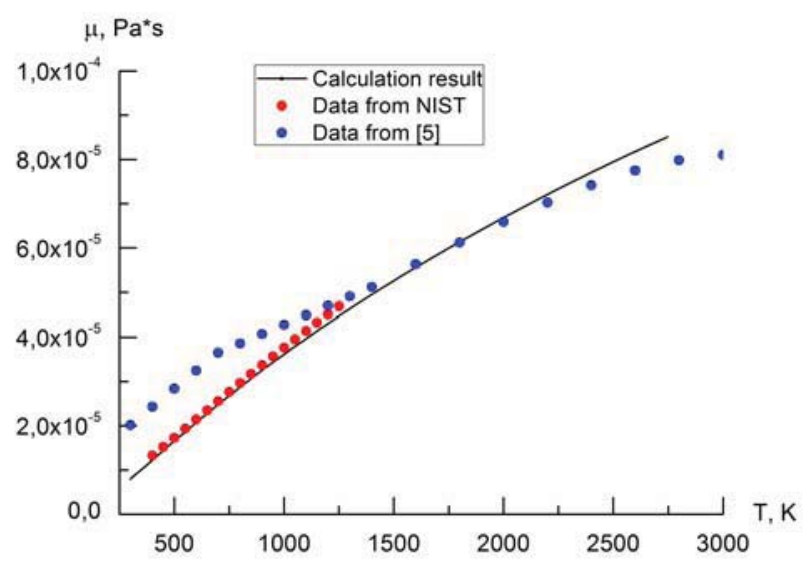

Figure 3: Comparison of dynamic viscosity with experimental data for water vapor

In Fig. 4 comparison of vapor heat conductivity with experiment is shown. The maximum calculation error makes $10 \%$.

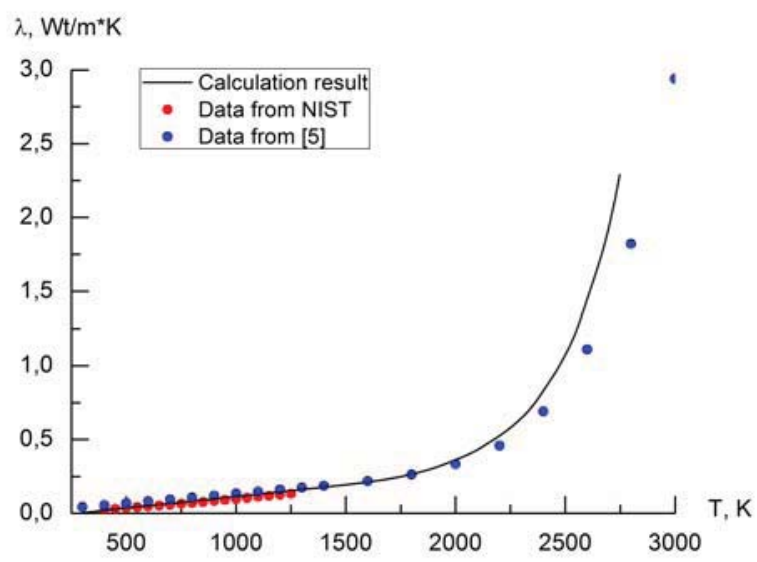

Figure 4: Comparison of heat conductivity with experimental data for water vapor

In Fig. 5 comparison of the air dynamic viscosity with experiment is shown. Data for comparison was received from the book [6]. The calculation error makes $8,5 \%$.

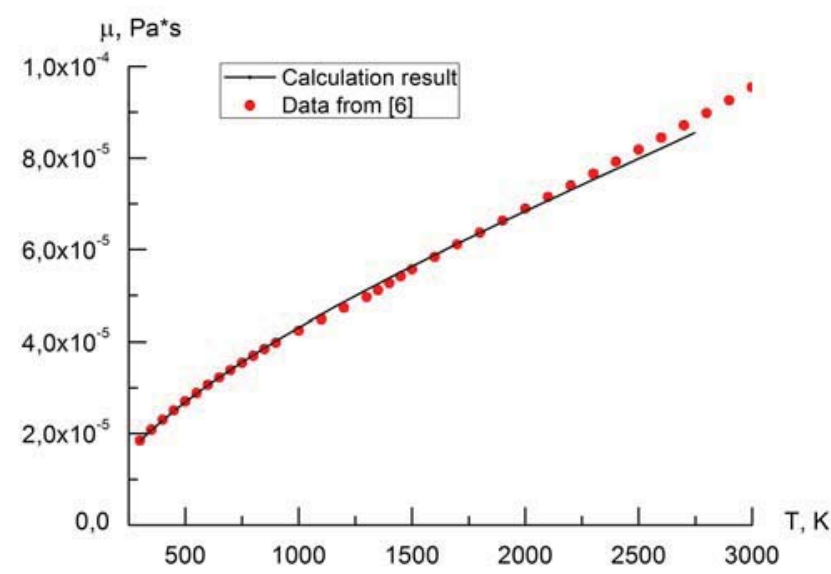

Figure 5: Comparison of kinematic viscosity with experimental data for air 
In Fig. 6 comparison of the air heat conductivity with experimental data is shown. The calculation error makes $10 \%$.

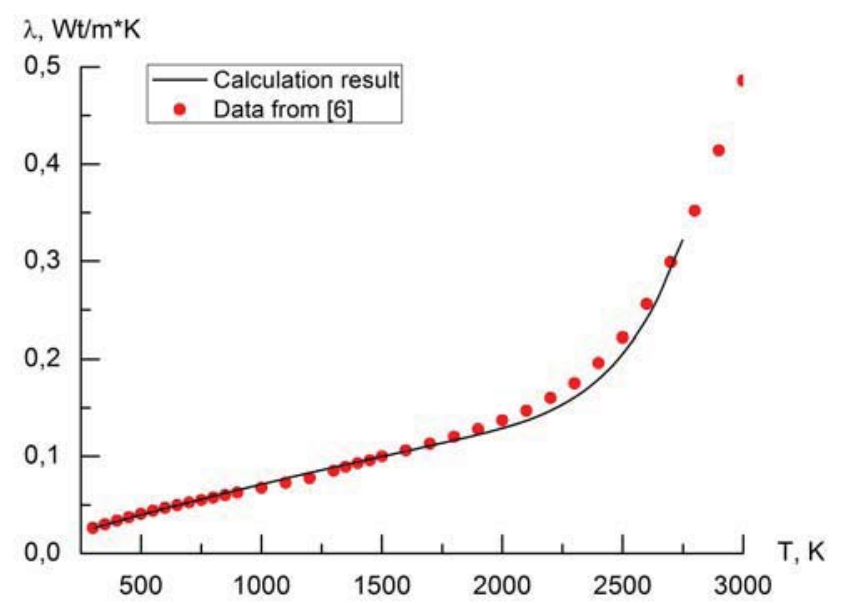

Figure 6: Comparison of heat conductivity with experimental data for air

Besides, the results of calculations of viscosity and thermal conductivity of the combustion products of two types of coal are presented. On this figures are shown the kinematic and dynamic viscosities, frozen thermal conductivity and thermal conductivity of chemical reactions of two coals from Kuznetskiy coal basin. The first coal is TROK I and the second coal is CC2CCPOK I.

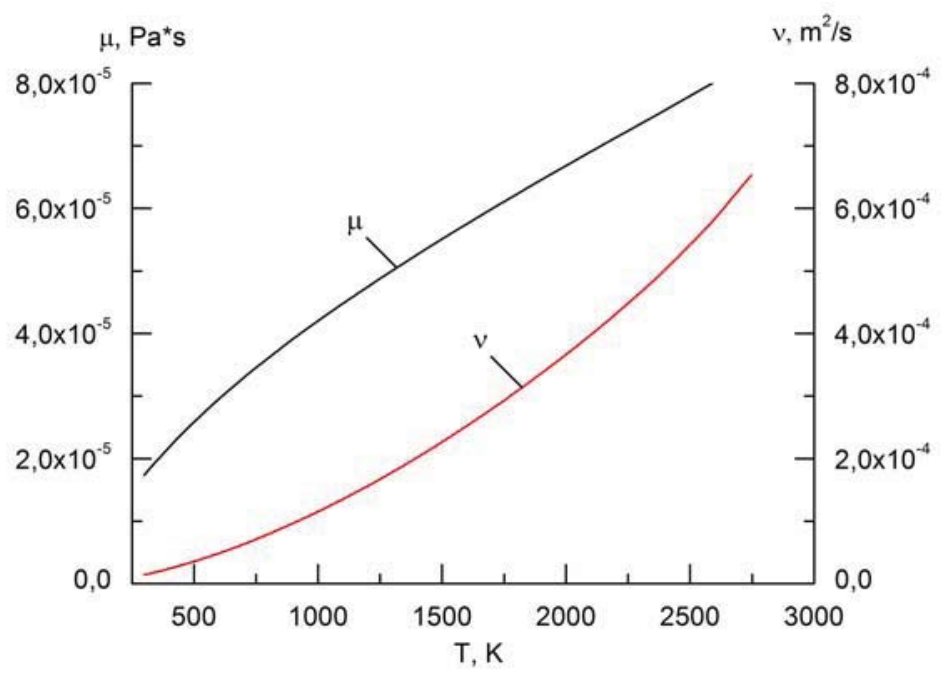

Figure 7: Kinematic and dynamic viscosities of coal TROK I 
$\mu, \mathrm{Pa}^{*} \mathrm{~s}$

$v, \mathrm{~m}^{2} / \mathrm{s}$

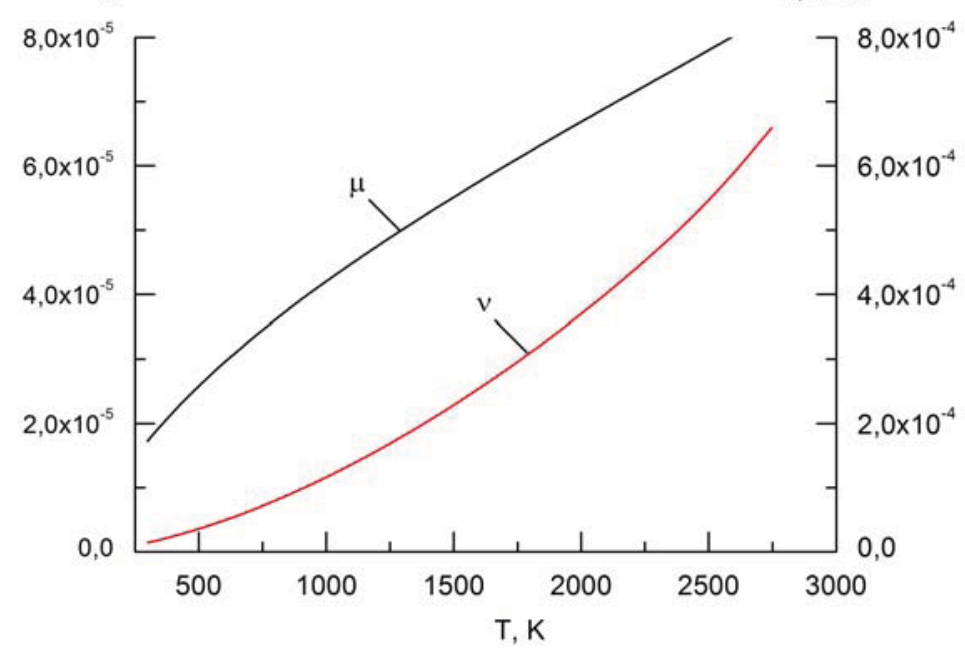

Figure 8: Kinematic and dynamic viscosities of coal CC2CCPOK I

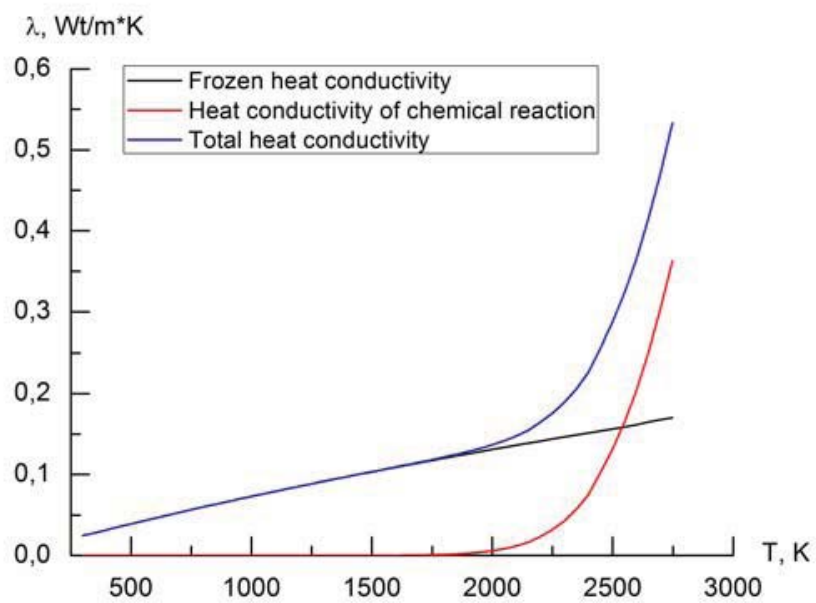

Figure 9: Heat conductivity of coal TROK I

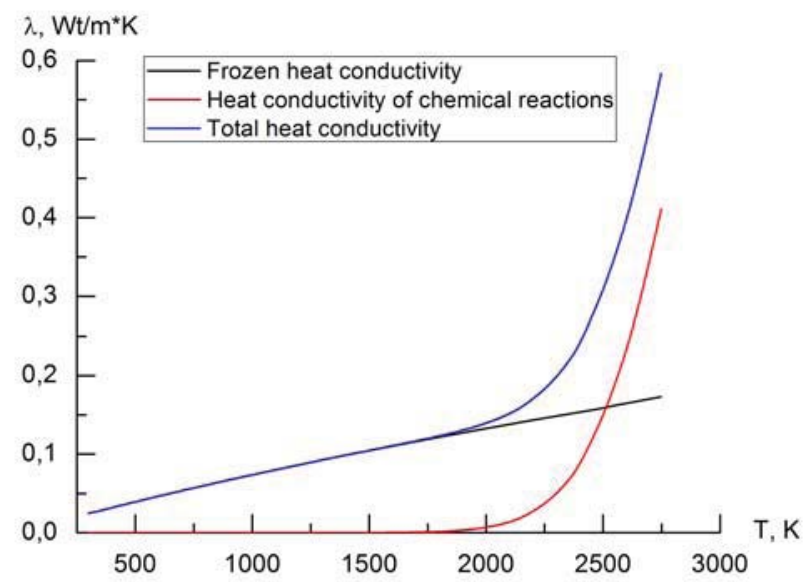

Figure 10: Heat conductivity of coal CC2CCPOK I 
Work is executed with the support Russian Basic Research Fund Grant № 10-0800468.

\section{REFERENCES}

[1] Hirschfelder J.O., Curtiss Ch.F., Bird R.B.: Molecular theory of gases and liquids, $1961,929 \mathrm{p}$

[2] Mason E.A., Monchick L.: Heat conductivity of polyatomic and polar gases, J. Chem. Phys., 1962, V. 36, № 6, P. 1622-1639

[3] Monchick L., Yun K.S., Mason E.A.: Formal kinetic theory of transport phenomena in polyatomic gas mixtures, J. Chem. Phys., 1963, V. 39, № 3, P. 654-669

[4] Shmelkov Y.B., Samujlov E.V. Termodynamicheskoe issledovanie fazoviz i himicheskih prevrasheniy pri gorenii tverdih topliv (in Russian) [English translation: Thermodynamic research of phase and chemical transformation during combustion of solid fuels] // Butlerovskie soobsheniya. 2011. V. 25. № 8. .67-74.

[5] Vargaftik N.B. Spravochnik po teplofizicheskim svoystvam gazov i zhidkostey (in Russian) [English translation: Handbook of thermophysical properties of gases and liquids] M.: Nauka, 1972. 720 pages

[6] Vasserman A.A., Kazavchinskiy Ya.Z., Rabinovich V.A. Teplovizicheskie svoystva vozduha I ego komponentov (in Russian) [English translation: Thermophysical properties of air and its components] M.: Nauka, 1966. 375 pages 